\title{
Evaluation of Small Bowel Bacterial Overgrowth Syndrome (SBBOS) in Egyptian Patients with Unexplained Gastrointestinal Symptoms: Histopathologic Features and Clinical Correlates in an Under Recognized Entity
}

\author{
Yasser S. Sheta ${ }^{1}$, Abdallah Nawara ${ }^{2}$, Elsayed A. Elgohary ${ }^{3}$, Abeer M. Hafez ${ }^{4}$, Samar S. Morsi ${ }^{5}$ \\ ${ }^{1,2,3}$ Department of Internal medicine, Faculty of Medicine, Zagazig University \\ ${ }^{4}$ Department of Pathology, Faculty of Medicine, Zagazig University \\ ${ }^{5}$ Department of Medical Microbiology\& Immunology Faculty of Medicine, Zagazig University
}

\begin{abstract}
Small bowel bacterial overgrowth syndrome (SBBOS) is a disorder of excessive bacterial growth in the small intestine. Unlike the colon (or large bowel), which is rich with bacteria, the small bowel usually has fewer than $10^{4}$ organisms per milliliter. Patients with bacterial overgrowth typically develop symptoms including nausea, bloating, vomiting, diarrhea, malnutrition, weight loss and mal-absorption which is caused by a number of mechanisms. Morphologic changes associated with this condition have not, to our knowledge, been studied in detail. Objective: To better characterize the histopathologic changes associated with SBBOS by comparing the clinico-pathologic features of patients with SBBOS (duodenalaspirate cultures with $\geq$ 105 colony-forming units $[\mathrm{CFU}] / \mathrm{mL})$ to controls with cultures found to be negative $(<105 \mathrm{CFU} / \mathrm{mL})$. Design: We included 28 consecutive patients with SBBOS and 21 controls in the series. Each duodenal biopsy was assessed for the following features: villous to cryptratio, intraepithelial lymphocytosis, crypt apoptoses, basal plasmacytosis, cryptitis/villitis, pepticduodenitis, erosions/ulcers, eosinophilia, and absence of goblet and Panethcells; and correlated with clinical features andculture results. Results: Decreased villoustocrypt ratio( $<3: 1)$ was more frequent inSBBOS than controls $(25 \%$ versus $5 \% ; P=<0.01)$. There were no significant differences in any of the other histologic features. Clinically, patients in the SBBOS group were older than the age of controls (mean,58.4 \pm 11.7 yearsversus $50 \pm 10.4$ years; $P=<0.05$ ), and they were more likely to have one of the known predisposing factors for bacterial over growth (68\% versus 38\%; $P=<0.05)$. Other Clinical features, including presenting symptoms, were similar. Conclusions: Villous blunting is the only feature more common of SBBOS than controls. More than half of biopsies from SBBOS patients are histologically unremarkable. Therefore, SBBOS needs to be considered as a potentialetiology for gastrointestinal symptom seven when duodenal biopsies are found to be normal.
\end{abstract}

Keywords: SIBO, jeujeunal culture, histopathology, biopsy, hydrogen breath test

\section{Introduction}

The upper intestinal tract was once thought to be a sterile environment; however, low concentrations of various bacteria are now widely accepted to live within or attached to its luminal surface. These bacteria are thought to be present from the time of birth and through adulthood, living in symbiosis with the human host. This relationship is thought to be vital for normal digestive processes, immunity, and intestinal development. Bacterial species usually present include lactobacilli, enterococci, oral streptococci, and other gram-positive aerobic or facultative anaerobes (Sieczkowska et al., 2015).

Various etiological processes can disrupt mechanisms that keep the number of these bacteria low. These include structural abnormalities (congenital or surgical) and disorders that cause decreased gastric acidity, reduced peristaltic activity, and mucosal damage or atrophy (Enko et al., 2015). Small intestinal bacterial overgrowth has also been reported in progressive systemic sclerosis, jejuna diverticulosis, $33 \%$ of patients with portal hypertension, $36 \%$ of those with chronic renal failure, $59 \%$ of uncomplicated acute colonic diverticulosis, $54 \%$ of overt hypothyroidism, $44 \%$ of acromegaly, and $96 \%$ of Cohn's disease with small-bowel strictures (Braun et al., 2015,
Mooney et al., 2015, Lauritano et al., 2007).Bacterial overgrowth can cause a variety of symptoms, many of which are also found in other conditions, making the diagnosis challenging at times (,Paul et al., 2010 \&Sieczkowska et al., 2015). Many of the symptoms are due to mal absorption of nutrients due to the effects of bacteria which either metabolize nutrients or cause inflammation of the small bowel impairing absorption. The symptoms of bacterial over growth include nausea, flatus, constipation, bloating, abdominal distension, abdominal pain or discomfort, diarrhea, fatigue, and weakness. Children with bacterial overgrowth may developmal nutrition and have difficulty attaining proper growth (Sieczkowska et al., 2015 \& Jan et al., 2010). Several methods have been used to detect SBBOS, but each has its disadvantages. The gold standard for diagnosis is a small intestinal aspirate culture showing growth of $\geq 10^{5}$ colony-forming units $[\mathrm{CFUs}] / \mathrm{mL}$ of duodenal or jejunal fluid(Elphick 2tal 2006).Noninvasive breath tests may be used to make a diagnosis of SBBOS, but these are labor-intensive and have shown wide-ranging sensitivity and specificity (Simre and Stotzer, 2996 \& Enko et al., 2015). Another Concern is the (minor) radiation exposure in breath testing using $14 \mathrm{C}$-xylose or $14 \mathrm{C}$ glycocholic acid (Guannarsson et al., 2007). The role of duodenal morphology in evaluating for SBBOS is not entirely clear. Scanning electron microscopy has shown

\section{Volume 4 Issue 11, November 2015}




\section{International Journal of Science and Research (IJSR) \\ ISSN (Online): 2319-7064}

Index Copernicus Value (2013): 6.14 | Impact Factor (2014): 5.611

derangements of villous architecture and injury to enterocytes and their microvilli (Fagundes et al., 2000)Higher counts of immunoglobulin (Ig) A-producing plasma cells in thelaminapropria and CD8+ lymphocytes in the villous epithelium exist in some cases of SBBOS, but demonstration requires immunohisto chemistry and mucosal morphometry (Riordan et al 2001). Only a few studies of routine light microscopic changes in SBBOS have been published, and these are complicated by conflicting results, different methods of diagnosis, and small numbers of patients (Haboubi et al., 1999 \& King et al., 1979).In this study we try to delineate the histopathologic features of SBBOS detectablein a routine pathology practice. Identification of specific histopathologic features or its absence in this condition may be helpful to direct thediagnostic workup and therapy in patients with vague prolonged gastrointestinal symptoms

\section{Materials and Methods}

\section{Study Population}

This study was carried out in the gastroenterology unit of Internal Medicine, Microbiology and Histopathology departments, Faculty of Medicine, Zagazig University in Egypt. All the preliminary participants in the study referred to diagnostic upper gastrointestinal endoscopic examination for evaluation of unexplained gastrointestinal symptoms not responding to routine symptomatic medications such as nausea, bloating, vomiting, diarrhea, malnutrition, weight loss and mal-absorption for more than one month from June 2013 till May 2014. Both duodenal or jejunal aspirate cultures and corresponding duodenal biopsies was taken. Cultures were considered positive when there was growth of $\%$ at least $10^{5} \mathrm{CFUs} / \mathrm{mL}$ of gram-negative bacteria, aerobic or anaerobic, and negative when there was less than $10^{5} \mathrm{CFUs} / \mathrm{mL}$. Patients were excluded from the study if there was a history of upper gastrointestinal Cohn's disease or recent infection with enteric pathogens or if there was a clinical diagnosis of celiac disease or celiac serologic markers were found to be unequivocally positive.

The final study population comprised 49 consecutive patients meeting the above criteria: 28 patients $(57.1 \%)$ with positivecultures and 21 control patients (41.9\%) with negative cultures. Mandatory routine approval of the official ethical committeewas obtained from the Review Board plus informed consent from all the participants was taken.

\section{Clinical Data}

Thorough initial history taking and clinical evaluation of the all of the participants of the study focusing on age, sex, presenting symptoms, serologic tests for gluten sensitivity (antigliadin $\mathrm{IgA}$ and $\mathrm{IgG}$, tissue transglutaminase $\mathrm{IgA}$ and IgG antibodies), documented vitamin or mineral deficiencies, albumin level, presence of ascites, history of uppergastrointestinal surgery, concomitant gastrointestinal orcolonic diseases, endoscopic appearance of the upper gastro intestinal tract, including evaluation for any structural abnormalities and any other medical conditions that might predispose the patient to SBBOS, such as portal hypertension orchronic renal failure.

\section{Bacteriological analysis}

The aspirated jejunal fluid which was transported in Robertson Cooked Meat broth (already diluted 1:10) was serially diluted further $(1: 100,1: 1,000)$ in phosphate buffer containing $1 \%$ peptone. Homogenized biopsy sample was also serially diluted $(1: 10,1: 100,1: 1,000), 20 \mu \mathrm{L}$ of a specific dilution each of the fluid/homogenized mixture was inoculated onto 5 separate culture plates. The total bacterial count was assessed using Miles and Misra method (Miles AA and Misra SS, 1983). The dilution which yielded countable colonies was used for computing the bacterial counts. The average number of colony counts per plate (i.e., per $20 \mu \mathrm{L}$ ) was calculated for every dilution. The culture media used for aerobic culture were chocolate agar, 5\% sheep blood agar and MacConkey's medium. Qualitative anaerobic cultures were done directly from the RCM tube (without dilution) onto 5\% sheep blood agar. The plates were incubated anaerobically in an anaerobic jar at $37^{\circ} \mathrm{C}$ for $48 \mathrm{~h}$. The total colony forming units (CFU) in jejunal fluid per $\mathrm{mL}$ and jejunal biopsy per gram were calculated by the following formulae for jejunal fluid and biopsy, respectively (Chandra et al., 2010).

$\underline{\text { No. of CFU per } 20 \mu \mathrm{L} \text { of fluid inoculated }} \times \frac{1}{20} \times$ dilution $\times 1000$

$$
\begin{aligned}
& \frac{\text { No. of CFU per } 20 \mu \mathrm{L} \text { of suspension inoculated }}{\text { Weight of the biopsy in gm }} \times \frac{1}{20} \\
& \times \text { dilution } \times 1000
\end{aligned}
$$

Cultures were considered positive for SIBO if the total bacterial count was $\geq 105 \mathrm{CFU}$ per $\mathrm{mL}$ of fluid or per gram of biopsy tissue (Justensen et al., 1984).Different colonies were selected according to their morphological characteristics and purified by successive sub culturing on nutrient agar and identified phenotipically based on standard methods (Collee et al.,1996)

\section{Antimicrobial susceptibility}

Antimicrobial susceptibility patterns of positive cultures for SIBO were determined by Kirby and Bauer disk diffusion method on Mueller Hinton (MH) agar plates ( Oxoid, UK). The antibiotic discs used were Ampicillin $(10 \mu \mathrm{g})$, Ampicillin-clavulanic acid $(10 / 10 \mu \mathrm{g})$, Piperacillintazobactam $(100 / 10 \mu \mathrm{g})$, Cefalexin $(30 \mu \mathrm{g})$, Cefuroxime $(30 \mu \mathrm{g})$ Ceftazidime $(30 \mu \mathrm{g})$, Cefotaxime $(30 \mu \mathrm{g})$, Amikacin $(30 \mu \mathrm{g})$, Ciprofloxacin $(10 \mu \mathrm{g})$ and TrimethoprimSulfamethoxazol (1.25/23.75 $\mu \mathrm{g})$, (Oxoid, UK). These antibiotics were selected as these are orally administrated except for Cefuroxime \& amikacin and therefore they are likely to be preferred by the clinicians in the treatment of SIBO. The plates were then incubated at $35-37^{\circ} \mathrm{C}$ for $24 \mathrm{~h}$. The zones of inhibition diameter were measured and interpreted as sensitive, intermediate and resistant isolates using Clinical Laboratory Standards Institute reference values, CLSI M100-S18.10

\section{Histopathologic Evaluation}

All duodenal biopsies had been fixed in formalin and processed routinely for hematoxylin-eosin staining of 4mmsections. Two of us (P.J.L. and T.-T.W.) were blinded to the culture results and clinical information and jointly 


\section{International Journal of Science and Research (IJSR) ISSN (Online): 2319-7064 \\ Index Copernicus Value (2013): 6.14 | Impact Factor (2014): 5.611}

assessed the biopsies for the following features: (1) villous to crypt (v:c) ratio,(2) number of surface and crypt intraepithelial lymphocytes, (3)number of crypt apoptoses, (4) basal plasmacytosis, (5) neutrophilic cryptitis or villitis, (6) peptic duodenitis, (7) accompanying erosions or ulcers, (8) increased mucosal eosinophils, and (9)abnormal absence of goblet cells and/or Paneth cells. Villous length to crypt depth ratio was considered abnormal if it was less than $3: 1$ in well-oriented biopsy fragments. Intraepithelially mphocytosis was evaluated by counting the number of lymphocytes within the villous epithelium in the area of highestlymphocyte density after scanning the biopsy fragments at low power. Cases were categorized as normal if $\leq 20$ lymphocytes per100 epithelial cells) or increased (21-40, 41-60, 61-80, and >801ymphocytes per 100 epithelial cells). Crypt intraepitheliallymphocytosis was evaluated in a similar fashion. For cryptapoptosis, any number greater than 5 apoptotic bodies per 10crypts was considered abnormal. Basal plasmacytosis was characterized by lymphoplasmacytic inflammation located between the muscularis mucosae and the base of the crypts with or without a qualitative increase in mononuclear cells in the intercryptal spaces and villi. We defined peptic change histologically as gastric foveolar metaplasia of the small-bowel epithelium and increased intramucosal Brunner glands in post bulb arbiopsies. Because there are no welldefined reference range foreosinophil counts in small-bowel lamina propria, the determination of increased mucosal eosinophils was subjective; we also considered anything more than rare intraepithelial eosinophils to be abnormal.

\section{Statistical Analysis}

Fisher exact test and $t$ test were used to compare the SBBOS and control groups for categoric and noncategoric data, respectively. Two-tailed $\mathrm{P}$ values, .05 were considered significant.

\section{Results}

\section{Clinical Features}

The demographic data are summarized in Table 1.Patients with SBBOS were on average older than controls (mean \pm $\mathrm{SD}, 58.4 \pm 11.7$ yearsversus50 \pm 10.4 years; $P=<0.05$ ). The SBBOS and control groups had similar presenting symptoms, with diarrhea $(54 \% ; 15$ of 28$)$, weight loss $(21 \%$; 6 of 28$)$,abdominal pain $(25 \% ; 7$ of 28$)$, and abdominal bloating $(29 \% ; 8$ of 28$)$ being the most common symptoms in patients with SBBOS, and with diarrhea $(62 \%$; 13 of 21$)$,abdominal pain $(29 \% ; 6$ of 21$)$, nausea $(24 \% ; 5$ of 21$)$, and weight loss $(19 \% ; 4$ of 21$)$ reported most commonly in controls. A slight female predominance was present in both groups (SBBOS, 54\%, 15 of 28; and control, $57 \%, 12$ of 21 , respectively; $\mathrm{P}=>0.05)$.As expected, conditions that are known to predispose to bacterial overgrowth were more prevalent in the SBBOS group (Table 2): $68 \%$ of patients with SBBOS (19 of 28) had predisposing conditions as compared with only $38 \%$ (9 of $21)$ in the control group $(P=<0.05)$. The most common condition in both groups was the use of acid lowering medications. The presence of a blind loop was significantly more frequent in the SBBOS group than in controls (11\% (3 of 28$)$ vs $5 \%$ ( 1 of 21$) ; \mathrm{P}=>0.05)$. One patients (4\%) with SBBOS had scleroderma, and another one (4\%) had chronic pancreatitis; none of the patients in the control group had these conditions.

Table 1: Demographics and Clinical Presentation

\begin{tabular}{|c|c|c|c|}
\hline Parameter & $\begin{array}{l}\text { SBBOS } \\
(n=28) \\
\text { No. }(\%)\end{array}$ & $\begin{array}{c}\text { Controls } \\
(n=21) \\
\text { No. }(\%)\end{array}$ & $P$ \\
\hline Male & $13(46)$ & $9(43)$ & $>0.05$ \\
\hline Female & $15(54)$ & $12(57)$ & $>0.05$ \\
\hline Age,y,mean $\pm(\mathrm{SD})$ & $58.4 \pm 11.7$ & $50 \pm 10.4$ & $<0.05$ \\
\hline \multicolumn{4}{|l|}{ Presenting symptoms/signs } \\
\hline Diarrhea & $15(54)$ & $13(62)$ & $>0.05$ \\
\hline Abdominalpain/cramping & $6(21)$ & $6(29)$ & $>0.05$ \\
\hline Weightloss & $7(25)$ & $5(24)$ & $>0.05$ \\
\hline Bloating & $8(29)$ & $4(19)$ & $>0.05$ \\
\hline Nausea & $5(18)$ & $5(24)$ & $>0.05$ \\
\hline Vomiting & $5(18)$ & $4(19)$ & $>0.05$ \\
\hline Constipation & $1(4)$ & $0(0)$ & $>0.05$ \\
\hline Hypoalbuminemia & $4(14)$ & $3(14)$ & $>0.05$ \\
\hline "Epigastricdiscomfort" & $4(14)$ & $3(14)$ & $>0.05$ \\
\hline Edema & $2(7)$ & $1(5)$ & $>0.05$ \\
\hline Vitamindeficiency & $3(11)$ & $2(10)$ & $>0.05$ \\
\hline Ascites/portalhypertension & $3(11)$ & $1(5)$ & $>0.05$ \\
\hline Abdominaldistention & $2(7)$ & $2(10)$ & $>0.05$ \\
\hline Steatorrhea & $1(4)$ & $1(5)$ & $>0.05$ \\
\hline Flatulence & $2(7)$ & $1(5)$ & $>0.05$ \\
\hline Proteinloosingenteropathy & $1(4)$ & $0(0)$ & $>0.05$ \\
\hline GERD & $3(11)$ & $3(14)$ & $>0.05$ \\
\hline Dysphagia/odynophagia & $0(0)$ & $1(5)$ & $>0.05$ \\
\hline
\end{tabular}

Table 2: Conditions Predisposing to Bacterial Overgrowth

\begin{tabular}{|c|c|c|c|}
\hline Parameter & $\begin{array}{c}\text { SIBO } \\
(n=28 \\
\text { No. }(\%)\end{array}$ & $\begin{array}{c}\text { Controls } \\
(n=21)\end{array}$ & No. $(\%)$ \\
& $15(54)$ & $7(33)$ & $<0.05$ \\
\hline Acid-lowering medications & $5(18)$ & $3(14)$ & $>0.05$ \\
\hline Diabetes (type 1 or2) & $3(11)$ & $1(5)$ & $>0.05$ \\
\hline Surgical blind loop & $1(4)$ & $1(5)$ & $>0.05$ \\
\hline Surgical adhesions(obstruction) & $1(4)$ & $0(0)$ & $>0.05$ \\
\hline Chronic renal failure & $1(4)$ & $0(0)$ & $>0.05$ \\
\hline Scleroderma & $1(4)$ & $0(0)$ & $>0.05$ \\
\hline Chronicpancreatitis & $27(96)$ & $11(52)$ &.$<0.01$ \\
\hline Total & & &
\end{tabular}

\section{Small Intestinal Aspirate Cultures}

Enteroscopy was performed and both jejunal fluid and mucosal biopsies were obtained in 40 patients. Total colony count $\geq 105$ were in 28 out of 40 patients. Aerobes were isolated in $28 / 28$ and anaerobe in $2 / 28$ with positive culture (Table 3). One bacterial species were grown in cultures of 22 patients and two bacterial species were grown in cultures of 6 patients. Both the culture of jejunal biopsy and jejunal fluid yielded similar results with respect to presence or absence of growth. 


\section{International Journal of Science and Research (IJSR) \\ ISSN (Online): 2319-7064}

Index Copernicus Value (2013): 6.14 | Impact Factor (2014): 5.611

Table 3: Frequency of isolation of different bacteris of patients with SIBO

\begin{tabular}{|l|l|}
\hline Organism & Frequency of isolation \\
\hline $\begin{array}{l}\text { Aerobes } \\
\text { Escherichia coli }\end{array}$ & 10 \\
\hline Klebsiella pneumoniae & 7 \\
\hline Streptococcus species & 6 \\
\hline Enterococcus spp & 3 \\
\hline Staphylococcus aureus & 2 \\
\hline Pseudomonas aeruginosa & 1 \\
\hline Acinetobacter baumanii & 1 \\
\hline Citrobacter spp & 1 \\
\hline Proteus spp & 1 \\
\hline $\begin{array}{l}\text { Anaerobes } \\
\text { Bacteroides fragilis } \\
\text { Bacteroides melaninogenicus }\end{array}$ & 1 \\
\hline
\end{tabular}

\section{Sensitivity testing}

In vitro sensitivity to commonly used orally absorbed antibiotics showed (table4) that bacteria isolated from small bowel were more often sensitive to ciprofloxacin and amikacin than to other groups of antibiotics.

Table 4: Resistance pattern of the isolated bacteria to various antibiotics ( $\%$ percentage)

\begin{tabular}{|c|c|c|c|c|c|c|c|c|c|c|c|}
\hline Bacteria & 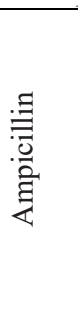 & 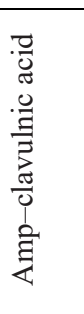 & 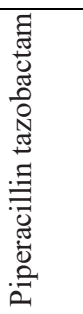 & 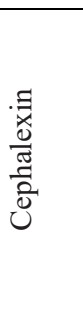 & 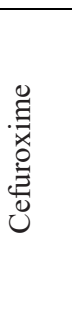 & 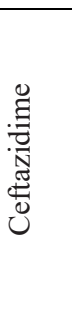 & 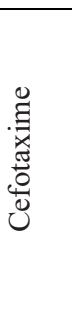 & 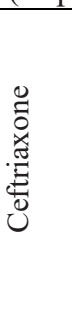 & 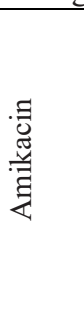 & 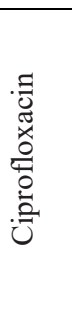 & 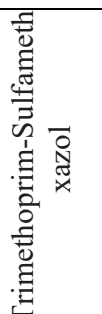 \\
\hline Escherichia coli $(n=10)$ & 100 & 40 & 20 & 40 & 40 & 40 & 40 & 40 & 0 & 50 & 70 \\
\hline Klebsiella pneumoniae $(n=7)$ & 100 & 71 & 43 & 43 & 43 & 43 & 43 & 43 & 0 & 14 & 100 \\
\hline Streptococcus species $(n=6)$ & 16 & 0 & 0 & 0 & 0 & 0 & 0 & 0 & 0 & 0 & 0 \\
\hline Enterococcus $\operatorname{spp}(n=3)$ & 33 & 33 & 0 & 0 & 0 & 0 & 0 & 0 & 0 & 0 & 0 \\
\hline Staphylococcus aureus(2) & 100 & 50 & 50 & 0 & 0 & 0 & 0 & 0 & 0 & 50 & 0 \\
\hline Pseudomonas aeruginosa $(n=2)$ & 100 & 100 & 50 & 100 & 0 & 50 & 50 & 50 & 0 & 0 & 50 \\
\hline Acinetobacter baumanii $(n=1)$ & 100 & 100 & 100 & 100 & 100 & 100 & 100 & 100 & 100 & 0 & 100 \\
\hline Citrobacter $\operatorname{spp}(n=1)$ & 100 & 0 & 0 & 0 & 0 & 0 & 0 & 0 & 0 & 0 & 0 \\
\hline Proteus spp $(n=1)$ & 100 & 100 & 100 & 100 & 0 & 100 & 100 & 100 & 0 & 0 & 100 \\
\hline Bacteroides fragilis & 0 & 0 & 0 & 0 & 0 & 0 & 0 & 0 & 0 & 0 & 100 \\
\hline Bacteroides melaninogenicus & 0 & 0 & 0 & 0 & 0 & 0 & 0 & 0 & 0 & 0 & 100 \\
\hline
\end{tabular}

\section{Histology}

The histologic findings are summarized in Table 3.Patients with SBBOS were more likely to have architecturally abnormal duodenal biopsies, with a v:c ratio of less than $3: 1$ in $7(25 \%)$ of cases with SBBOS but in only 1 controls $(5 \%$; $\mathrm{P}<0.05$; Figures 1 and $2, \mathrm{~A})$. In contrast, there were no significant differences between the 2 groups in any of the Otherhisto pathologic features, including villous and cryptintraepithelial lymphocytosis, crypt apoptoses, basal plasmacytosis, neutrophiliccryptitis/ villitis, erosion/ulcers, increased mucosal eosinophils, presence of goblet and Paneth cells, or peptic duodenitis (Figures 2, B, and 3).Overall, 15 of the duodenal biopsies from patients with SBBOS (54\%) were judged to be within reference range, whereas the other $46 \%$ (13 of 28 ) demonstrated one or morehistologic abnormalities. In the control group, there were slightly higher numbers of biopsies considered normal $(62 \%$; 13 of 21$)$, but that difference was not statistically significant $(\mathrm{P}>0.05)$.
Table 3: Histologic Features of DuodenalBiopsies

\begin{tabular}{|c|c|c|c|}
\hline Parameter & $\begin{array}{c}\text { SBBOS } \\
(n=28) \\
\text { No.(\%) }\end{array}$ & $\begin{array}{c}\text { Controls } \\
(n=21) \\
\text { No. }(\%)\end{array}$ & $P$ \\
\hline Any histologicabnormality & $13(46)$ & $8(36)$ & $>0.05$ \\
\hline v:cratio(<3:1) & $7(25)$ & $1(5)$ & $<0.01$ \\
\hline $\begin{array}{c}\text { Intraepitheliallymphocytosisa } \\
\text { Villi }\end{array}$ & $6(21)$ & $4(19)$ & $>0.05$ \\
\hline Crypts & $2(7)$ & $1(5)$ & $>0.05$ \\
\hline Increasedeosinophils & $4(14)$ & $3(14)$ & $>0.05$ \\
\hline Basalplasmacytosis & $2(7)$ & $1(5)$ & $>0.05$ \\
\hline Pepticduodenitis & $2(7)$ & $2(10)$ & $>0.05$ \\
\hline Neutrophiliccryptitis/villitis & $2(7)$ & $2(10)$ & $>0.05$ \\
\hline Cryptapoptoses(>5per10 crypts) & $2(7)$ & $1(5)$ & $>0.05$ \\
\hline Erosions/ulcers & $0(0)$ & $0(0)$ & $>0.05$ \\
\hline Absent goblet/Panethcells & $0(0)$ & $0(0)$ & $>0.05$ \\
\hline
\end{tabular}

v:c ratio, villous to crypt ratio.

a .20 lymphocytes per 100 epithelial cells. 


\section{International Journal of Science and Research (IJSR) ISSN (Online): 2319-7064}

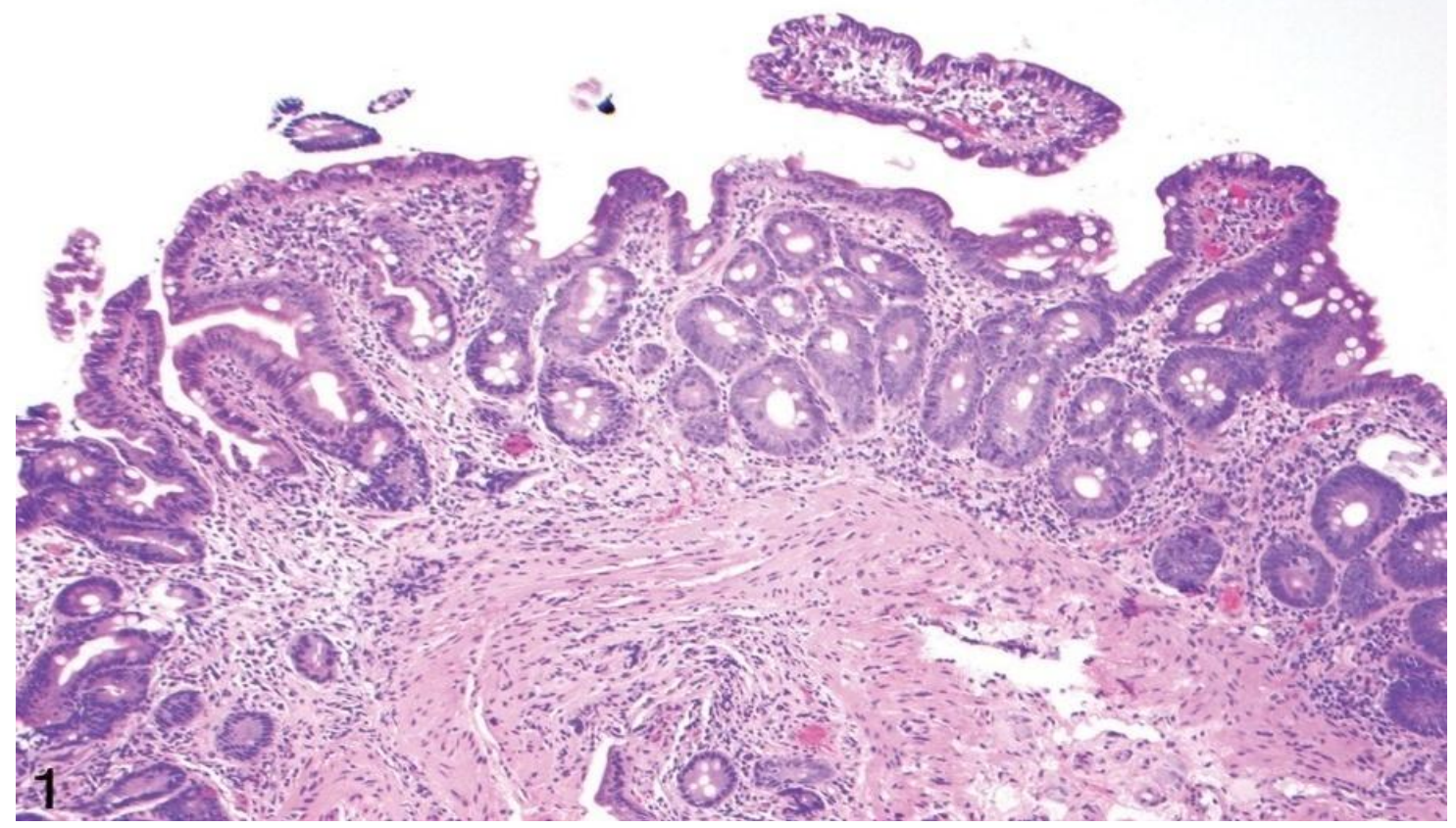

Figure 1: Partial villous atrophy with villous to crypt ratio of $1: 1$, without intraepithelial lymphocytes is seen in a case with SBBOS (hematoxylin-eosin, X100).

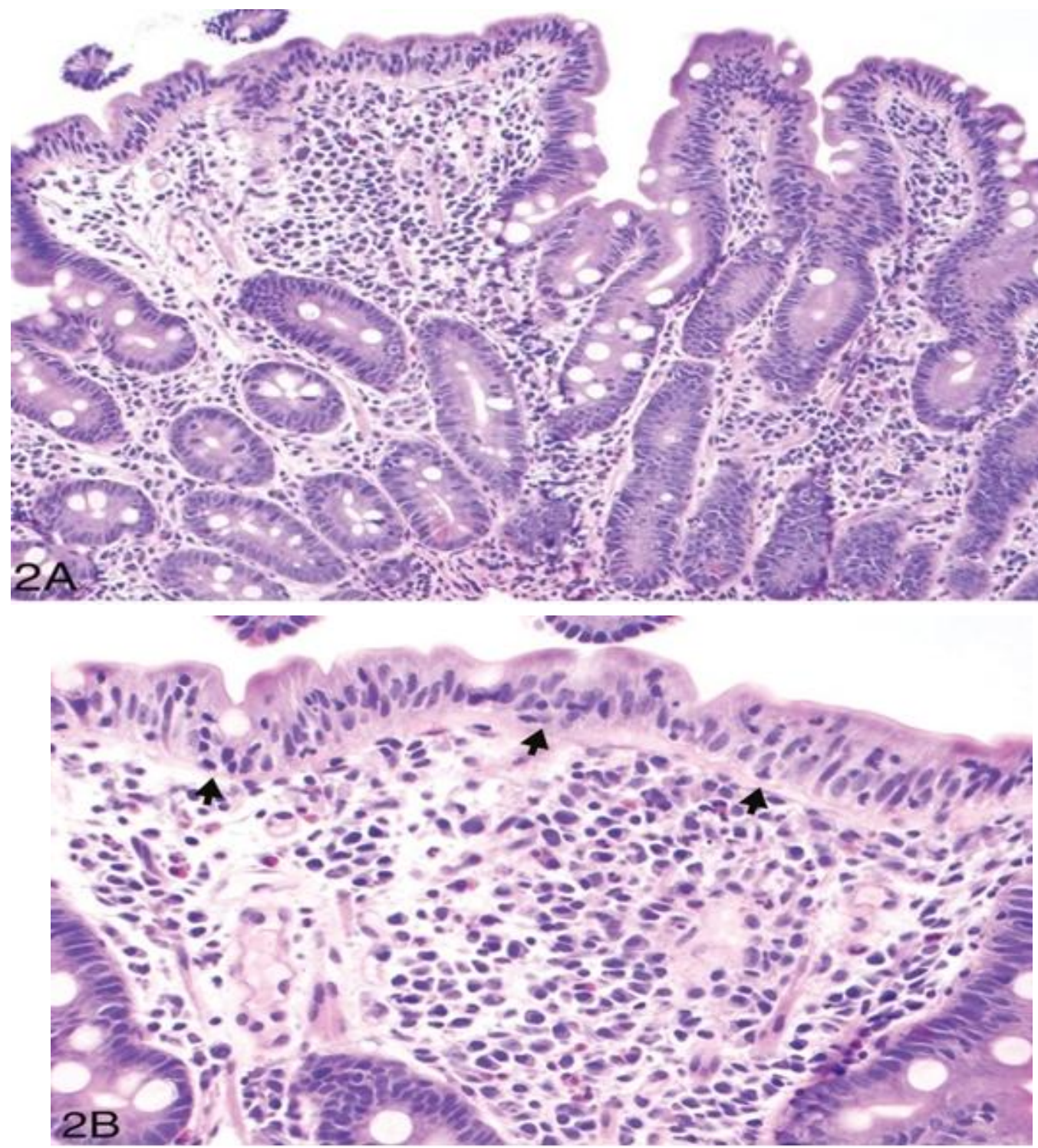

Figure 2: A, Partial villous blunting with villous to crypt ratio of $1: 1 . B$,Intraepithelial lymphocytosis (arrows) in a case with SBBOS(hematoxylin-eosin,X200[A] andX400[B]).

Volume 4 Issue 11, November 2015 


\section{International Journal of Science and Research (IJSR) ISSN (Online): 2319-7064}

Index Copernicus Value (2013): 6.14 | Impact Factor (2014): 5.611

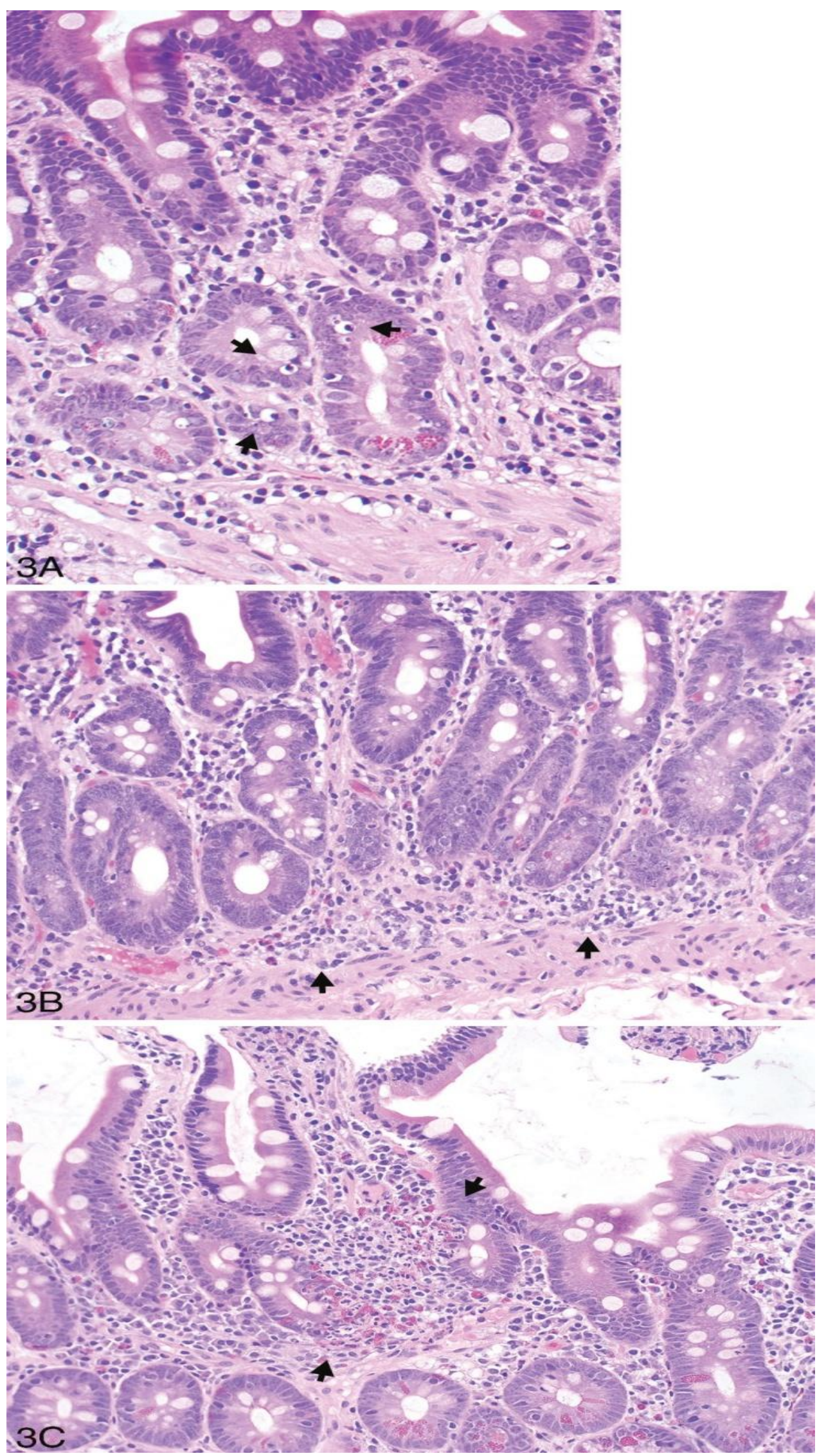

Figure 3: Histologic features occasionally seen in SBBOS, including (A) increased crypt apoptoticbodies(arrows);(B)basalplasmacytosischaracterizedbylymphoplasmacyticinflammationlocatedbetweenthemusculari smucosaeandthebaseofthecrypts(arrows); and(C)neutrophiliccryptitis(arrows)(hematoxylin-eosin, original magnificationsX400).

Volume 4 Issue 11, November 2015 www.ijsr.net 


\section{International Journal of Science and Research (IJSR) \\ ISSN (Online): 2319-7064 \\ Index Copernicus Value (2013): 6.14 | Impact Factor (2014): 5.611}

\section{Discussion}

Human intestinal microbiota create a complex poly microbialecology. This is characterized by its high population density, wide diversity and complexity of interaction. Any dysbalance of this complex intestinal microbiome, both qualitative and quantitative, might have serious health consequence for a macro-organism, including small bowel bacterial overgrowth syndrome (SBBOS).(Enko et al., 2015, Jan et al., 2010) There are several endogenous defense mechanisms for preventing bacterial overgrowth: gastric acid secretion, intestinal motility, intact ileo-caecalvalve, immunoglobulins within intestinal secretion and bacteriostatic properties of pancreatic and biliary secretion.(Enko et al., 2015)SBBOS is a very heterogeneous syndrome characterized by an increased number and/or abnormal type of bacteria in the small bowel. Most authors consider diagnostic of SBBOS to be the finding of $\geq 10^{5}$ colony-forming units[CFUs] $/ \mathrm{mL}$ of duodenalor proximal jejunal aspiration.[Sieczkowska et al., 2015, Elphic et al., 2006]Aetiology of SBBOS is usually complex, associated with disorders of protective antibacterial mechanisms (e.g. achlorhydria, pancreatic exocrine insufficiency, immune deficiency syndromes), anatomical abnormalities (e.g. small intestinal obstruction, diverticula, fistulae, surgical blind loop, previous ileocaecal resections) and/or motility disorders (e.g. scleroderma, autonomic neuropathyin diabetes mellitus, post-radiation enteropathy, small intestinal pseudoobstruction). In some patients more than one factor may be involved(Paul et al., 2010). Bacterial overgrowth can cause a variety of symptoms, many of which are also found in other conditions, making the diagnosis challenging at times (Sieczkowska et al., 2015). Many of the symptoms are due to mal absorption of nutrients due to the effects of bacteria which either metabolize nutrients or cause inflammation of the small bowel impairing absorption. The symptoms of bacterial overgrowth include nausea, flatus, constipation, bloating, abdominal distension, abdominal pain or discomfort, diarrhea, fatigue, and weakness (Jan et al., 2010). In this study we try to delineate the histopathologic features of SBBOS detectable in a routine pathology practice. All 49 patients in our study had prolonged gastrointestinal symptoms, and all were diagnosed as having - or not having - SBBOS by duodenal or jejunal aspirate cultures (considered to be the diagnostic gold standard for bacterial overgrowth). As expected, there were some clinical differences between SBBOS cases and controls. Patients with SBBOS were on average older than patients without $\mathrm{SBBOS}($ mean $\pm \mathrm{SD}, 58.4 \pm 11.7$ years versus $50 \pm 10.4$ years; $P=<0.05$ ), underscoring prior studies that have shown a higher prevalence of SBBOS in elderly patients who are more likely to suffer from altered gut motility, poor nutrition, and/or medical conditions that predispose them to bacterial overgrowth(Donald et al., 1999). In our study, patients with SBBOS were also more likely to have one or more risk factors for bacterial overgrowth $(68 \%$ versus $38 \% ; \quad P=<\quad 0.05)$.Numerous conditions have been associated with SBBOS including blind loop, surgical adhesions, scleroderma, diabetes, chronic pancreatitis, and intestinal dysmotility (Braun et al., 2015, Mooney et al., 2015, Lauritano et al., 2007)). We included use of acid-lowering medications as a possible risk factor, although it is likely not a strong one(Fujimori et al., 2015). These medications were common in both SBBOS $(54 \% ; 15$ of 28$)$ and controls $(33 \% ; 7$ of 21$)$, but even if this factor is disregarded, the results remain statistically significant $(P<0.05)$. Aside from age and background risk factors, the 2 groups were similar. In particular, there was a marked overlap in presenting symptoms, with diarrhea and abdominal pain being the most common indications for small bowel biopsy in both SBBOS cases and control cases. Several studies suggest that SIBO is much more common in the general population than previously thought and that it is frequently under diagnosed. For example, Teo et al (Teo et al., 2004) prospectively studied 87 consecutive patients with chronic diarrhea, and SBBOS was by far the most frequent etiology, accounting for symptoms in $48 \%$ of cases $(\mathrm{n}=42)$, whereas irritable bowel syndrome accounted for only $13 \%(n=11)$. There is also increasing evidence that SBBOS may be the underlying etiology in some cases of irritable bowel syndrome, which is currently the most common diagnosis rendered in gastroenterology practice (Posseurd et al., 2007). Pimental et al2000 used lactulose hydrogen breath testing to evaluate for SBBOS in 202 patients with a clinical diagnosis of irritable bowel syndrome and obtained positive results in $78 \%$ (n 5 158). Although breath tests suffer from lack of specificity, in the Pimentelet al 2000 study, eradication of SBBOS after antibiotic therapy was significantly associated with improvement in symptoms of diarrhea and abdominal pain, to the extent that $48 \%$ of subjects who achieved eradication $(\mathrm{n}=97)$ no longer met clinical criteria for irritable bowel syndrome.

The present study has demonstrated that the culture of jejunal biopsy yields results similar to fluid with respect to presence of growth, nature of organisms.

It was found that the predominant Gram positive organism was streptococcus species and the predominant Gram negative organism was Escherichia coli. This is accordance with the earlier report from the west (Bouhnik et al., 1999). We found frequent resistance to Ampicillin-clavulanic acid and Trimethoprim-sulfamethoxazole that are often used in the treatment of SIBO. This is in accordance with Ghoshal et al (2003) but it is in contrast to an western report showing infrequent resistance to most antibiotics (Bouhnik et al., 1999) These discrepancies might be explained by differing practice of antibiotic use in different countries. Frequent resistance to commonly used antibiotics in Egypt might owe to frequent unnecessary use of these antibiotics. Most of bacteria isolated were sensitive to both ciprofloxacin and Amikacin. However, ciprofloxacin may be preferred over Amikacin, since ciprofloxacin can be given orally and therefore, may have in frequent side effects. Patients with SIBO often need long-term and repeated courses of antibiotics and therefore, those with lesser toxicity and lower systemic absorption would be preferred

Histologically, we found that modestarchitectural distortion was the most common abnormality in SBBOS. Villous blunting was present in $25 \%$ of SBBOS biopsies ( 7 of 28 ) but only $5 \%$ of controls ( 1 of $21 ; \quad P=<0.01$ ). Lymphocytosiswithin villous epithelium was also slightly more frequent in SBBOS $(21 \%$; 6 of 28$)$ than in controls 


\section{International Journal of Science and Research (IJSR) \\ ISSN (Online): 2319-7064}

Index Copernicus Value (2013): 6.14 | Impact Factor (2014): 5.611

(19\%; 4 of 21), but this did not reach statistical significance. Overall, $54 \%$ of duodenal biopsies from patients with SBBOS (15 of 28 ) and $64 \%$ of biopsies from symptomatic controls (13 of 21) in our study population were within histologic reference range. The high rate of histologically "normal" biopsies does not negate the pathogenic role of bacterial overgrowth in symptomatic patients. It has been hypothesized that excess colonic flora within the small intestine can impede fat digestion by deconjugating bile acids and hindering the formation ofmicelles, that these bacteria can induce vitamin B12deficiency, and that they can result in osmotic or secretorydiarrhea through the production of organic acids, free bileacids, fatty acids, and other organic acids(Camp et al., 2009). All of these proposed mechanisms can coexist with microscopically healthy small bowel mucosa. Overall, the published findings related to the light microscopic findings in SBBOS are based on studies of small numbers of patients, use varying diagnostic tests to define SBBOS, and have included control groups that range from truly healthy patients to patients with diarrhea-predominant irritable bowel syndrome. The results of these studies have been conflicting. Ament et al(1972) found mild to moderate villous blunting and increased cellularity in the lamina propria in 3 of 3 patients $(100 \%)$ studied but emphasized the patchy nature of these abnormalities in the numerous biopsies taken from these patients. In contrast, Riordan et $\mathrm{al}(2001)$ reported no differences in villous height, crypt depth, or v:cratiobetween 26 patients with SBBOS and 26 controls.

In summary, our results show that only approximately half of small intestinal biopsies from symptomatic patients with a gold standard diagnosis of SBBOS show any histologic abnormality on routine hematoxylin-eosin examination. When abnormalities are present (most commonly villous blunting or increased intraepithelial lymphocytes) they are typically mild and relatively nonspecific. Therefore, when trying to determine the etiology for a patient's upper gastrointestinal symptoms, both pathologists and gastroenterologists should be aware of the limitations of histology in diagnosing, suggesting, or ruling out SBBOS. Small-bowelbiopsies remain extremely important in the evaluation for other gastrointestinal diseases (eg, celiac disease and pepticduodenitis), but if SBBOS is a diagnostic consideration then specific clinical or microbiologic testing for bacterial over growth should also be performed.

\section{References}

[1] Ament ME, Shimoda SS, Saunders DR, Rubin CE. Pathogenesis of steatorrhea in three cases of small intestinal stasis syndrome. Gastroenterology.1972;63(5):728-747.

[2] Braun-Moscovici Y, Braun M, Khanna D, BalbirGurman A, FurstDE. What tests should you use to assess small intestinal bacterial overgrowth in systemic sclerosis?.ClinExpRheumatol. 2015 Jul-Aug;33Suppl 91(4):117-122.

[3] Camp JG, Kanther M, Semova I, Rawls JF. Patterns andscales in gastrointestinal microbial ecology. Gastroenterology2009; 136: 1989-2002
[4] Chandra S, Dutta U, Noor MT, Taneja N, Kochhar R, Sharma M\& $r$ Singh K: Endoscopic jejunal biopsy culture: a simple and effectivemethod to study jejunal microflora Indian J Gastroenterol (2010) 29:226-230

[5] Churchill Livingstone; 1996:131-49. Justesen T, Nielsen OH, Jacobsen IE, Lave J, Rasmussen SN. The normal cultivable microflora in upper jejunal fluid in healthy adults. Scand J Gastroenterol. 1984;19:279-82.

[6] Collee JG, Miles RS and Walt B: Tests for the identification of bacteria In: Mackie and McCartney Practical Medical Microbiology Edited by: Collee JG, Fraser AG, Marmion BP, Simmons A. New York:

[7] Donald IP, Kitchingmam G, Donald F, Kupfer RM. The diagnosis of small bowel bacterial overgrowth in elderly patients. J Am Geriatr Soc. 1992;40(7):692696.

[8] Elphick HL, Elphick DA, Sanders DS. Small bowel bacterial overgrowth: an underrecognized cause of malnutrition in older adults.Geriatrics. 2006;61(9):2126.

[9] Enko D, Kriegshäuser G, Kimbacher C, Stolba R, Mangge H, Halwachs-Baumann G. Carbohydrate Malabsorption and Putative Carbohydrate-Specific Small Intestinal Bacterial Overgrowth: Prevalence and Diagnostic Overlap Observed in an Austrian Outpatient Center.Digestion. 2015;92(1):32-8.

[10] Fagundes-Neto U, De Martini-Costa S, Pedroso MZ, Scaletsky IC. Studies of the small bowel surface by scanning electron microscopy in infants with persistent diarrhea. Braz J Med Biol Res. 2000;33(12):14371442.

[11] Fujimori S. What are the effects of proton pump inhibitors on the small intestine?.World J Gastroenterol. 2015 Jun 14;21(22):6817-9

[12] Gunnarsson M, Leide-Svegborn S, Stenstro“m K, et al. Long-term biokinetics and radiation exposure of patients undergoing 14C-glycocholic acid and 14Cxylose breath tests. Cancer BiotherRadiopharm. 2007;22(6):762-771.

[13] Haboubi NY, Lee GS, Montgomery RD. Duodenal mucosal morphometry of elderly patients with small intestinal bacterial overgrowth: response to antibiotic treatment. Age Ageing. 1991;20(1):29-32.

[14] Jan B, Jiri C, DarinaK, MiroslavF, StanislavR.Small intestinal bacterial overgrowth syndrome .World $J$ Gastroenterol2010 June 28; 16(24): 2978-2990

[15]King CE, Toskes PP. Small intestine bacterial overgrowth. Gastroenterology.1979;76(5, pt 1):10351055.

[16]Lauritano EC, Bilotta AL, Gabrielli M, et al. Association between hypothyroidism and small intestinal bacterial overgrowth. J ClinEndocrinolMetab. 2007;92(11):4180-4184.

[17] Miles AA, Misra SS. The estimation of the bactericidal power of the blood. J Hyg. 1938;38:732-49.

[18] Mooney PD, Hayman J, Pickering G, Sanders DS.Are we underestimating the prevalence of small intestinal bacterial overgrowth in irritable bowel syndrome?.NeurogastroenterolMotil. 2015 Aug;27(8):1190-1

[19] Paul J, Susan C, AbrahamM, Joseph A. Small Intestinal Bacterial Overgrowth Histopathologic Features and 


\section{International Journal of Science and Research (IJSR) \\ ISSN (Online): 2319-7064}

Index Copernicus Value (2013): 6.14 | Impact Factor (2014): 5.611

Clinical Correlates in an Underrecognized Entity. Arch Pathol Lab Med. 2010;134:264-270

[20] Pimentel M, Chow EJ, Lin HC. Eradication of small intestinal bacterial overgrowth reduces symptoms of irritable bowel syndrome. Am J Gastroenterol.2000; 95 (12):3503-3506.

[21] Posserud I, Stotzer PO, Björnsson ES, Abrahamsson $H$, Simre'n M. Small intestinal bacterial overgrowth in patients with irritable bowel syndrome. Gut. 2007;56(6):802-808

[22] Resmini E, Parodi A, Savarino V, et al. Evidence of prolonged orocecal transit time and small intestinal bacterial overgrowth in acromegalic patients. J ClinEndocrinolMetab. 2007;92(6):2119-2124.

[23] Riordan SM, McIver CJ, Wakefield D, Duncombe VM, Thomas MC, Bolin TD. Small intestinal mucosal immunity and morphometry in luminal overgrowth of indigenous get flora. Am J Gastroenterol. 2001;96(2):494-500.

[24] Sieczkowska A, Landowski P, Kamińska B, Lifschitz.Small Bowel Bacterial Overgrowth in Children: A Comprehensive Review. C.J PediatrGastroenterolNutr. 2015;42(7):733-740.

[25] Simre'n M, Stotzer PO. Use and abuse of hydrogen breath tests. Gut. 2006;55(3):297-303

[26] Teo M, Chung S, Chitti L, et al. Small bowel bacterial overgrowth is a common cause of chronic diarrhea. J GastroenterolHepatol. 2004;19(8):904-909

[27] Bouhnik Y, Alain S, Attar A, Flourie B, Raskine L, Sanson-Le Pors MJ and Rambaud JC: Bacterial populations contaminating upper gut in patients with small intestinal bacterial overgrowth syndrome Am J Gastroenterol 1999, 94:1327-31. 